\title{
IoT Technologies as Instruments for SMEs' Innovation and Sustainable Growth
}

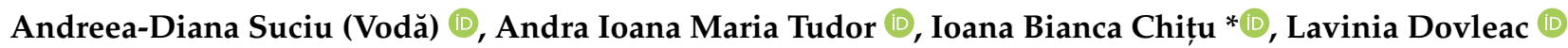 \\ and Gabriel Brătucu (D)
}

check for updates

Citation: Suciu (Vodă), A.-D.; Tudor, A.I.M.; Chițu, I.B.; Dovleac, L.; Brătucu, G. IoT Technologies as Instruments for SMEs' Innovation and Sustainable Growth.

Sustainability 2021, 13, 6357. https:// doi.org/10.3390/su13116357

Academic Editor: Danuta Zawadzka

Received: 21 April 2021

Accepted: 27 May 2021

Published: 3 June 2021

Publisher's Note: MDPI stays neutral with regard to jurisdictional claims in published maps and institutional affiliations.

Copyright: (c) 2021 by the authors. Licensee MDPI, Basel, Switzerland. This article is an open access article distributed under the terms and conditions of the Creative Commons Attribution (CC BY) license (https:// creativecommons.org/licenses/by/ $4.0 /)$.
Faculty of Economic Sciences and Business Administration, Transilvania University of Braşov, 500068 Braşov, Romania; andreea.suciu@unitbv.ro (A.-D.S.); andra.tudor@unitbv.ro (A.I.M.T.); lavinia.dovleac@unitbv.ro (L.D.); gabriel.bratucu@unitbv.ro (G.B.)

* Correspondence: ioana.chitu@unitbv.ro

\begin{abstract}
This paper studies specific aspects related to the adoption of Internet of Things (IoT) technologies and the impact they have on the sustainable growth of Small and Medium Enterprises (SMEs) in the Romanian IT industry. It was considered that digital marketing in general, and IoT in particular, have enormous potential for the aforementioned entities, and the acceptance and adoption of IoTs by companies in different sectors can significantly influence the way they operate, leading to sustainable growth. Primary data obtained from quantitative marketing research based on a questionnaire were analyzed. The results showed that although a large proportion of the Romanian IT industry SMEs use advanced marketing technologies, relatively few of those have integrated IoT solutions to date, mainly due to specific cost challenges. Nevertheless, the outcomes highlight that these companies are aware of the IoT's benefits and place the adoption of such solutions among their priorities in order to achieve sustainable growth of their businesses. Based on the research results, the main proposal for the business environment is to design viable marketing programs for these companies, as well as to allocate resources for business development aimed at educating human resources to effectively address specific internal and external activities through IoT for sustainable development.
\end{abstract}

Keywords: sustainable growth; IoT; SME; digital marketing; IT industry in Romania

\section{Introduction}

Small and medium enterprises (hereinafter referred to as SMEs) are one of the essential pillars of the development of the European economy [1] and play an important role in transition economies [2] on their way to sustainable growth [3]. In the Organization for Economic Co-operation and Development (OECD) area, SMEs represent $99 \%$ of all business, offer $60 \%$ of jobs, and provide between $50 \%$ and $60 \%$ of added value [4].

In Romania, SMEs represent $99.7 \%$ of the total number of companies (slightly below the European average, which is $99.8 \%$ ), and $65.8 \%$ of the total active population is employed by the SMEs (with the European average being $66.6 \%$ ). From the point of view of average productivity, however, Romanian SMEs register an average of EUR 15,100, below the European average of EUR 44,600 [5].

Based on the values of the five variables of Connectivity, Human Capital, Use of Internet, Integration of Digital Technology, and Digital Public Services, Romania is part of the "Digital Challengers" group of European countries with a low level of digitalization but high potential [6].

The year 2020 has accelerated the process of adopting new technologies, which has become a real challenge for companies, with the digitization of most areas of activity being a priority. From this point of view, Romania ranks 26th in the European Union (hereinafter the EU) in the Digital Economy and Society Index (DESI) ranking published by the European Commission in 2020 [7]. Under the current conditions defined by the novel 
coronavirus (COVID-19) pandemic, SMEs are under great pressure to find ways to increase the sustainability of their businesses, and the application of Internet of Things (hereinafter referred to as IoT) technologies can support this [8]. According to a study of 1200 European SMEs from the start of the pandemic until July 2020, SMEs that have adopted new digital technologies have had the greatest chances to identify new opportunities for business survival and development, reaching a rate twice as high as those that have not digitized [9].

Romanian SMEs are in the process of transition to industry-specific digital technology 4.0, having the desire and knowledge to implement change in their organizations, but do not yet have sufficient resources [10] to achieve sustainable growth. In addition to financial resources, other barriers indicated by Romanian SMEs include the lack of public financing policies, difficulties gaining access to relevant market information or to new technologies, issues in gathering new partners, and problems in long-term forecasting and in finding qualified human resources [11]. The results of a study conducted on 84 companies in Romania showed that there were no significant differences between SMEs and large enterprises in terms of their attitude towards the integration of IoT-related technologies. However, there were several differences in perception and use, determined by the number of employees and the markets to which they were addressed (regional, national, international) [12].

Based on the above aspects, the authors consider that IoT technologies present an enormous potential for individuals [13], communities (smart cities) [14], and SMEs in Romania, including the evolution of digital marketing, and that their acceptance and adoption by companies from different sectors can significantly influence the ways in which these companies operate and lead to sustainable growth.

As Romanian SMEs generate half of the added value and up to two thirds of the jobs in the nonfinancial economy [15], the authors consider that investigating their current situation and determining the best action plans for achieving sustainable growth represents a major research topic for the Romanian economy.

Therefore, the main purpose of the paper was to analyze specific aspects of the adoption of IoT technologies in marketing activities and their impacts on SMEs from the information technology (IT) industry in Romania, based on the results of quantitative marketing research. IoT technologies can perform multiple roles in a company, providing both operational and strategic support [16], so the marketing research was conducted among employees holding management positions in the marketing or IT departments.

The novelty and the utility of the current study lie in the fact that the contribution of the IoT technologies to Romanian SMEs' sustainable growth was analyzed. The authors consider Romanian SMEs to be an important segment that has potential but still faces various pain points in implementing and using technologies to achieve sustainability. This raises the need to understand and build an accurate profile of Romanian SMEs to help them implement reliable sustainable growth plans and get the best out of the advanced technologies such as IoT.

The results of the research revealed that although a large proportion of small and medium-sized companies from the Romanian IT industry use advanced marketing technologies, relatively few have so far aimed to integrate IoT solutions, especially due to specific cost challenges. Although IoT technologies are not growing in popularity among SMEs in the IT industry, the research findings highlight their potential, indicating that IoT integration is a priority for these companies' future sustainable growth. At the same time, the research results proved the impact of the enterprises' size, both in terms of employees and expansion to new locations, on the adoption of IoT technologies by SMEs from the IT sector in Romania.

In order to achieve the intended goal, the paper is structured into four sections. Specifically, after the literature review, the research methodology is described, followed by the presentation of the research results and related discussions, and the final part includes a series of conclusions and proposals. 


\section{Literature Review}

The transition to Industry 4.0 represents a challenge for SMEs-a challenge with various technological, organizational, and management components. SMEs generally do not have the same opportunities as multinational enterprises. However, they have some advantages, such as "lower expectation profitability" and a simpler organizational system [17]. Studies have shown that SMEs do not use all the resources associated with Industry 4.0; they are often limited to cloud computing or the Internet of Things [18]. The main barriers for them are a lack of knowledge and the lack of strategic long-term plans [19]. Adopting new technologies, and innovation in general, acts as a "catalyst" for the sustainable growth of SMEs [20] and has positive effects on their performance [21]. At the same time, SMEs with a stronger orientation towards innovation could benefit from "external knowledge sourcing", a form of inbound open innovation [22].

Nowadays, we are increasingly witnessing the penetration of the new technologies into everyday life [13], and IoT technologies are considered a "universal panacea" [23], a "power that promises to change the future" [24], a strategy for survival and for sustainable growth of SMEs [25]. IoT is an increasingly used concept that has raised the interests of researchers [26,27], even if there is not a generally valid definition yet [28]. Essentially, it is an interconnected network of intelligent objects capable of transmitting the data via cable or wireless technologies [29]. IoT applies in various fields and sectors of activity (transport, health, governance, education, trade, agriculture, industry etc.) becoming a powerful weapon in competitive struggle $[27,29,30]$, or even a great business opportunity [31]. IoTtype solutions have become increasingly affordable and companies use them to quickly and efficiently adapt to market changes, improving consumer experiences [32]. Given the potential of the IoT in providing business opportunities and job creation, several national and European policies have been put in place to enable companies to be trained in the adoption and diffusion of such technologies [1]. These technologies are connected with other particularities of e-business, such as "changing the nature of entry threats, suppliers' power, buyers' power, threats from substitutes, and rivalry among existing firms" [33]. Solely investing in IoT does not guarantee the long-term success for the companies, as this should be correlated with other physical, managerial, and organizational resources [34]. The emergence and development of the new technologies require firms to rethink and innovate their business models [35-39], and to transform them into sustainable ones [40], by using service-oriented digitized approaches [41]. Both innovation-based and efficiencybased business models lead to increased performance for the SME, but in the countries which have stronger capabilities in firms it is the innovation that prevails, while the size of the SME emphasizes the efficiency [42]. The business models are reformulated so that firms sell the so-called "outcome-based services", and not products, thus guaranteeing the delivery of the "performance outcomes of products" [43]. To perform all these changes and to benefit from the opportunities that the IoT can bring, the companies have to go through a structural transformation of their processes to develop the necessary skills and to be convinced that the IoT fits their goals [44]. Business models should be designed based on the opportunities offered by Industry 4.0 (some researchers are calling it the "IoT Industry") [45]. The SMEs use different strategies for the implementation of Industry 4.0, and these strategies depend on the "internal motivation towards implementing Industry 4.0 and on the company's structural and technological characteristics" [46].

At the organizational level, the IoT involves long-term changes, the introduction of these new technologies having a short- and medium-term impact on the organizational process. At the individual level, the IoT can lead to increased employee stress and to rejection, as it requires the development of new skills [47]. The determinants of digitalization consist in the process engineering, digital culture, new technologies, central positioning of the customer, and digital marketing [48].

Some studies emphasize that the IoT contributes to the sustainable business performance of SMEs [25,49], as it allows for the better management of resources and a greater flexibility to adapt to the market conditions [50], and it improves the productivity and 
competitiveness of an enterprise [51]. However, the IoT looks rather complicated [52], and the decision to adopt IoT-type solutions involves a series of relatively high-cost investments, such as investments in technology acquisition and maintenance, as well as serious investments in employees training to allow for the use of the new technologies with optimal results [53]. A proper digital transformation is based on sensing and learning capabilities [38], and it requires the proper technology for the resilience of the systems [54]. Researchers have identified four stages regarding the involvement of SME in the adoption of the new digital technologies: digital awareness, digitization demand, digital collaboration, and digital transformation [55]. The adoption of IoT by SMEs is also linked to certain contextual factors and predictors such as: the competitive advantage, the management support, the external pressure of consumers and partners, and, ultimately, the government support [56]. The new context determines the market strategies of the companies to be oriented towards the digital and content marketing, which represent more different and effective concepts compared to the classic marketing approaches [31,57]. For instace, when promoting the ICT products in the online environment, it is better to emphasize the idea of quality, so the products to be perceived as more reliable for the consumers [58].

The change comes as a necessary adaptation to the upgrade in the lives of the consumers, who spend progressively more time online and who have different expectations from the providers, so the integration of digital tools becomes a condition for the survival of companies on the market [59], allowing them to be more receptive and efficient [32]. Digital marketing is defined as a process which involves the continuous adaptation of technology through which the companies collaborate with the customers and the partners to create, support, and deliver value for all the stakeholders [60]. Solutions such as Artificial Intelligence and the IoT are increasingly integrated into marketing strategies in order to better understand the consumers' behaviors and habits, to create relationships $[12,52,57,61]$, to increase their loyalty [62], to provide an immediate answer to customer demands [63], and ultimately to generate value for firms [52]. Likewise, digital marketing can reduce the costs and increase the capabilities to gain competitive advantage [39].

Studies on the adoption and integration of digital marketing by SMEs show that numerous SMEs are not aware of the potential the digital marketing detains, they lack sufficient knowledge and financial resources, they show deficiencies in the analysis of external environment, and, therefore, they miss the benefits and opportunities that these new tools offer [64-66]. Furthermore, the SMEs do not perceive the competitive advantage that can be gained by a better knowledge and understanding of the needs and behaviors of the consumers by using digital marketing technologies [67]. However, 2020 studies show that the top SMEs in the EU are increasingly taking advantage of the tools offered by digital marketing to create strong brands and secure sustainable growth [68].

\section{Methods and Materials}

In order to achieve the proposed goal, quantitative marketing research was performed. The primary data collection was based on the online distribution of a questionnaire. Data were analyzed in order to identify the integration and contribution of the IoT technologies to the marketing activities of SMEs from the Romanian IT industry.

\subsection{Research Objectives and Hypotheses}

The research objectives aimed to determine the degree of use of the digital marketing and advanced marketing technologies (such as the IoT solutions) in the SMEs of the IT industry in Romania.

The following objectives were considered appropriate in order to achieve the proposed goal:

- To quantify the degree of knowledge and understanding of the term "IoT" by the SMEs.

- To identify the types of advanced digital marketing technologies that SMEs use the most. 
- To determine the perception of the employees in management positions, in marketing or IT departments within SMEs on the use of the marketing budget for the IoT technologies.

- To establish the integration level of IoT technologies in SMEs.

- To identify the most important activities for which the respondents want to use the marketing budget.

- To determine the marketing activities that contribute to the development of effective digital marketing strategies on the IT market.

Some hypotheses were formulated to identify the perceptions of the respondents, to determine the current situation of the companies, to know their future plans and the influence factors related to the IoT. The hypotheses were defined as follows:

- There is no connection between the companies' expansion to new locations and the integration of advanced marketing technologies (1st hypothesis).

- There is no connection between the size of the companies based on the number of employees and the level of importance considered for IoT integration in digital marketing campaigns (2nd hypothesis).

\subsection{Sample Structure and Data Collection}

According to the SMEs Definition User Manual [69] developed by the European Commission, SMEs are companies with less than 250 employees and a turnover which does not exceed EUR 50 million, or a total annual balance sheet below EUR 43 million. As an analysis of the Romanian market was targeted, only the domestic and autonomous SMEs were considered, these being defined as enterprises that do not have capital or voting rights in a percentage higher than $25 \%$ in another company, and no other company holds more than $25 \%$ of its capital or voting rights [69]. The official statistics on the autonomous SMEs on the Romanian market show that, in 2020, there were 1016 active enterprises in the IT industry according to the previously defined criteria. Therefore, it was possible to apply a structured random sampling method to the research population, which in this case, is finite [70].

In order to identify the autonomous SMEs of the IT industry in Romania, official data were used and the researchers generated a list of all companies of interest. A series of filters were applied to create the final database, as follows:

- Fields of activity-including the following selections (National Classification of Economic Activities-NACE-codes):

- $\quad 6201$ Computer programming activities

- $\quad 6202$ Computer consultancy activities

- $\quad 6203$ Computer facilities management activities

- 6209 Other information technology and computer service activities

- Capital participation-with a minimum of $75 \%$

- Employees-between 1 and 249 (inclusive)

- Turnover-between 0 and EUR 50 million (inclusive)

Given the known size of the population, the authors determined the sample size in two steps.

The first step was to determine the sample size for a large/unknown population using Cochran's formula (Equation (1)):

$$
n_{0}=\frac{z^{2} \times p \times q}{E^{2}}
$$

where:

- $\quad n_{0}=$ recommended sample size according to Cochran's formula

- $E=$ accepted error $(\%)$

- $z=$ value in the distribution table for $\alpha=0.05$ 
- $\quad p=$ estimated proportion of an attribute that is present in the population

- $q=1-p$, estimate of variance.

As the $p$ and $q$ values are unknown, the authors considered the maximum level they can reach. In this case, the values were the following (Equation (2)):

- $p=50 \%$

- $q=50 \%$

- $E= \pm 5 \%$

- $z=1.96$ (for a $95 \%$ confidence level and the accepted error value $\alpha= \pm 5 \%$ ).

$$
n=\frac{1.96^{2} \times 50 \times 50}{5^{2}}=384
$$

As a second step, the sample size was corrected and adapted for a smaller, known population, using the formula in Equation (3):

$$
n=\frac{n_{0}}{1+\frac{\left(n_{0}-1\right)}{N}}
$$

where:

- $n=$ adjusted sample size

- $n_{0}=$ recommended sample size according to Cochran's formula

- $\quad N=$ population size

$$
n=\frac{384}{1+\frac{(384-1)}{1016}}=279
$$

Thus, for a $5 \%$ error, the sample size would be equal to 279 companies (Equation (4)). As shown, the adjustment (also called finite population correction) led to a reduction of the sample size.

Ultimately, 258 valid answers were obtained, the error in this case being calculated according to the formula in Equation (5):

$$
\begin{gathered}
E= \pm \sqrt{\frac{z^{2} \times p \times q \times(N-n)}{n \times(N-1)}} \\
E= \pm \sqrt{\frac{1.96^{2} \times 50 \times 50 \times(1016-258)}{258 \times(1016-1)}}= \pm 5.27 \%
\end{gathered}
$$

The final sample for quantitative research comprised 258 respondents. Thereby, the answers received from a large number of respondents allow the extrapolation of the results to the entire research population for an acceptable margin of error (Equation (6)).

Data concerning the research population and the sample structure, according to the two main criteria - the size of the companies and the field of activity, NACE code is presented in Tables 1 and 2. While the sample could not be declared valid according to the first criteria (size of the companies), mainly because of the reticence (for companies with 1-9 employees) and willingness (for companies with 150-249 employees) of the companies to provide answers, the authors chose an extra criterion to validate the sample (the field of activity), and applied the t-Student statistical test accordingly.

To test whether these differences (sample versus research population structure) are statistically significant, the t-Student test was performed based on the following hypotheses: $\mathrm{H}_{0}$ : The sample structure according to the field of activity is equal to the structure of the research population $(\pi=p)$

$\mathrm{H}_{1}$ : The sample structure according to the field of activity differs from the structure of the research population $(\pi \neq p)$, 
Where $\pi$ represents the percent of companies (relative frequency) at the level of the research population and $p$ represents the percent of companies at the level of the sample.

Table 1. The structure of the studied companies according to the number of employees.

\begin{tabular}{ccccc}
\hline No. of Employees & $\begin{array}{c}\text { No. of SMEs in } \\
\text { the Total } \\
\text { Population }\end{array}$ & $\begin{array}{c}\text { \% of SMEs in the } \\
\text { Total Population }\end{array}$ & $\begin{array}{c}\text { No. of SMEs in } \\
\text { the Sample }\end{array}$ & $\begin{array}{c}\text { \% of SMEs in the } \\
\text { Sample }\end{array}$ \\
\hline $1-9$ & 555 & $55 \%$ & 54 & $21 \%$ \\
$10-49$ & 318 & $31 \%$ & 75 & $29 \%$ \\
$50-149$ & 108 & $11 \%$ & 59 & $23 \%$ \\
$150-249$ & 35 & $3 \%$ & 70 & $27 \%$ \\
\hline Total & 1016 & $100 \%$ & 258 & $100 \%$ \\
\hline
\end{tabular}

Table 2. The structure of the companies studied according to the field of activity.

\begin{tabular}{ccccc}
\hline NACE Code & $\begin{array}{c}\text { Number of SMEs } \\
\text { in the Total } \\
\text { Population }\end{array}$ & $\begin{array}{c}\text { The Share of } \\
\text { SMEs in the Total } \\
\text { Population }\end{array}$ & $\begin{array}{c}\text { Number of SMEs } \\
\text { in the Sample }\end{array}$ & $\begin{array}{c}\text { Share of SMEs in } \\
\text { the Sample }\end{array}$ \\
\hline 6201 & 714 & $70 \%$ & 179 & $69.3 \%$ \\
6202 & 198 & $20 \%$ & 52 & $20.5 \%$ \\
6203 & 18 & $2 \%$ & 5 & $1.8 \%$ \\
6209 & 86 & $8 \%$ & 22 & $8.4 \%$ \\
\hline Total & 1016 & $100 \%$ & 258 & $100 \%$ \\
\hline
\end{tabular}

The differences between the two percentages (at the research population and the sample level), calculated with the formula below (Equation (7)), are considered insignificant if the null hypothesis $(\pi=p)$ is accepted. The sample is valid in this case.

$$
t_{o b s}=\left|\frac{p-\pi}{S p}\right|=\left|\frac{p-\pi}{\sqrt{\frac{p \times(100-p)}{n}}}\right|
$$

In order to be able to compare the observed quantity with the theoretical one, and to make the optimal decision regarding the acceptance of one of the tested hypotheses, the authors first calculated $t_{\alpha ; d f}$, for $\alpha=0.05$ and a number of degrees of freedom $d f=n-1$, the final value being equal to 1.969 .

Taking into consideration the criterion regarding the number of employees while applying the t-Student test, the differences between the percentages of the population and those of the sample are significant (Table 1), and the sample cannot be considered valid. In this particular case, it was sought to validate the sample from the activity point of view (NACE code) (Table 2).

Various steps were followed in order to be able to validate the sample based on the second criterion. The value of $t_{o b s}$ was calculated for all the NACE codes considered and compared with the theoretical value of $t_{\alpha ; d f}$.

The following result was obtained for the field of activity with NACE code 6201 (Equation (8)):

$$
t_{o b s}=\left|\frac{69.3-70}{\sqrt{\frac{69.3 \times(100-69.3)}{258}}}\right|=0.084
$$

The following result was obtained for the field of activity with NACE code 6202 (Equation (9)):

$$
t_{o b s}=\left|\frac{20.5-19}{\sqrt{\frac{20.5 \times(100-20.5)}{258}}}\right|=0.237
$$


The following result, shown in Equation (10), was obtained for the field of activity with NACE code 6203:

$$
t_{\text {obs }}=\left|\frac{1.8-2}{\sqrt{\frac{1.8 \times(100-1.8)}{258}}}\right|=0.291
$$

In Equation (11) is shown the result obtained for the field of activity with NACE code 6209:

$$
t_{o b s}=\left|\frac{8.4-8}{\sqrt{\frac{8.4 \times(100-8.4)}{258}}}\right|=0.231
$$

Comparing the critical ratios obtained for all four of the NACE codes with the theoretical value, it resulted that $t_{o b s}<t_{\alpha ; d f}$ for all the analyzed cases. Therefore, following the application of the t-Student test in the case of percent, the sample could be declared valid according to the field of activity.

The high geographical dispersion of the studied companies led to the application of the questionnaire through the Computer Assisted Web Interviewing (CAWI) technique. The questionnaire was completed using the Google Forms application, part of the webbased Google Docs Editors suite developed by Google LLC, and it was active for 11 weeks. The data collection period was June-August 2020. The questionnaire included 22 questions, of which 18 aimed at collecting information related to the digitization of the SMEs of the IT industry in Romania, and the 4 final questions aimed to characterize both the respondents and the studied companies. The coding and the final database creation were manually processed. Data was analyzed using the IBM Statistical Package for Social Sciences (SPSS) program, v.19, New York, NY, USA.

\subsection{Applied Methods}

The authors performed two statistical tests to verify the two hypotheses of the paper. Firstly, the authors tested the 1st hypothesis assuming that there is no connection between the companies' expansion to new locations and the integration of advanced marketing technologies. To verify this assumption, the authors used the Chi-Square method. The main reason for this is that the Chi-Square tests are used for testing the relationships between categorical variables in the population which are independent. Therefore, the authors used the cross-tabulation in order to visualize the distribution of the two considered variables. The Chi-Square test compares the observed pattern of the responses to the expected pattern [71]. By expected pattern, one would understand the pattern if the considered variables were truly independent from each other. The Chi-Square statistics model is shown in Equation (12):

$$
X^{2}=\sum_{i=1}^{r} \sum_{j=1}^{c} \frac{\left(O_{i j}-E_{i j}\right)^{2}}{E_{i j}}
$$

Whereas,

- $O_{i j}$ refers to the observed frequencies for the contingency table placed at the intersection of the row $i$ and the column $j$;

- $E_{i j}$ denotes the expected frequencies for the contingency table placed at the intersection of row $i$ and column $j$.

The value obtained is compared with a theoretical value from the distribution table of Chi-Square according to the degrees of freedom $(d f)$ calculated using the formula in Equation (13).

$$
d f=(i-1) \times(j-1)
$$

To test the second stated hypothesis, which assumed that there is no connection between the size of companies based on the number of employees and the level of importance considered for the IoT integration in digital marketing campaigns, the authors chose to 
apply a nonparametric test (the Median Test) to assess whether the independent groups differ in central tendency. The principle of this method is that if the samples have the same median, they should have approximately the same proportion of observations above and below the median, irrespective of their distributions [72]. The calculation steps follow the Chi-Square method, with the amendment that the values at the sample level are distributed according to their position in relation to the median, and the contingency table is computed consequently.

\section{Results and Discussion}

In the Romanian market, the integration of advanced or new marketing technologies such as IoT, Artificial Intelligence, or Bots, can be a challenge in terms of specific costs, especially for the SMEs [53]. In comparison to other countries across Europe, there are studies emphasizing that Romania is still not ranked highly in terms of digitization, taking the second to last place after Bulgaria. Nevertheless, the country proves a strong growth potential in the "digital economy" [6].

The current marketing research revealed that although the IoT concept is not very popular among the SMEs of the IT industry as in other studies [64-67], it has fantastic potential because the IoT adoption and integration is a priority for the future. More than half of the analyzed companies (64.2\%) already integrated some of the new technologies into their marketing processes, as other studies revealed [68]. Although the most popular technology among the analyzed companies is Artificial Intelligence, two companies had integrated the IoT technologies.

Another question aimed to identify whether SMEs in the Romanian IT industry integrate advanced marketing technologies. The results show that only $36 \%$ of the SMEs integrate technologies such as IoT, Artificial Intelligence, etc.

In order to identify the opinion of the respondents regarding the activities they use the most in order to develop an effective digital marketing strategy, an ordinal scale (semantic differential) was used, where 1 means "To a very small extent" and 5 "To a very large extent".

As shown in Figure 1, the activity related to "Defining a clear budget for the marketing digitalization", obtained the highest score, with an average of 4.11 points on a scale from 1 to 5 ; the IoT solutions were evaluated with the lowest score. There are several factors that can determine the low interest in the integration of IoT, the influence of certain variables being analyzed in the hypothesis testing section.

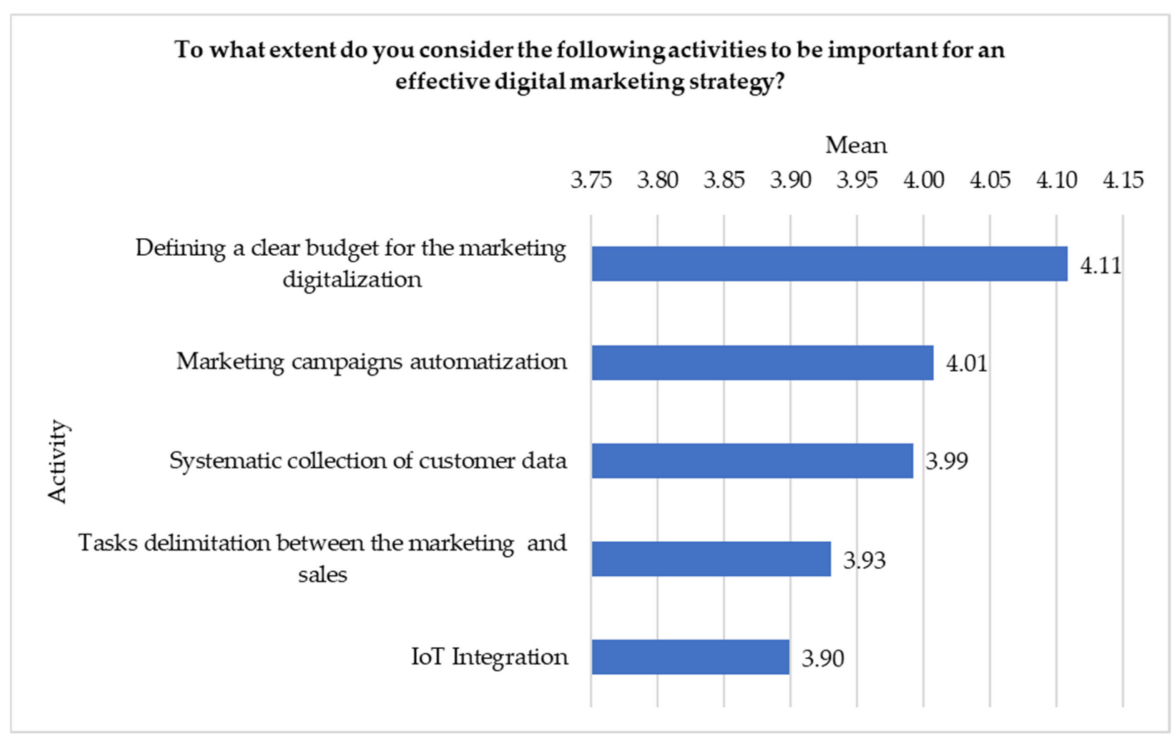

Figure 1. Important activities for developing an effective digital marketing strategy. 
However, when discussing the marketing budget utilization plan, the IoT Integration in marketing activities is at the top of the preferences among the interviewees. In order to identify the most important actions for which the respondents want to use the marketing budget in the near future, the authors used a question constructed on the nominal scale with multiple-choice possibility.

It can be seen in Figure 2 that the "IoT Technologies integration" occupies the second position, nominated by $18.6 \%$ of respondents. The result is an optimistic one, showing an increasing trend in terms of IoT adoption among the SMEs of the IT industry in the Romanian market.

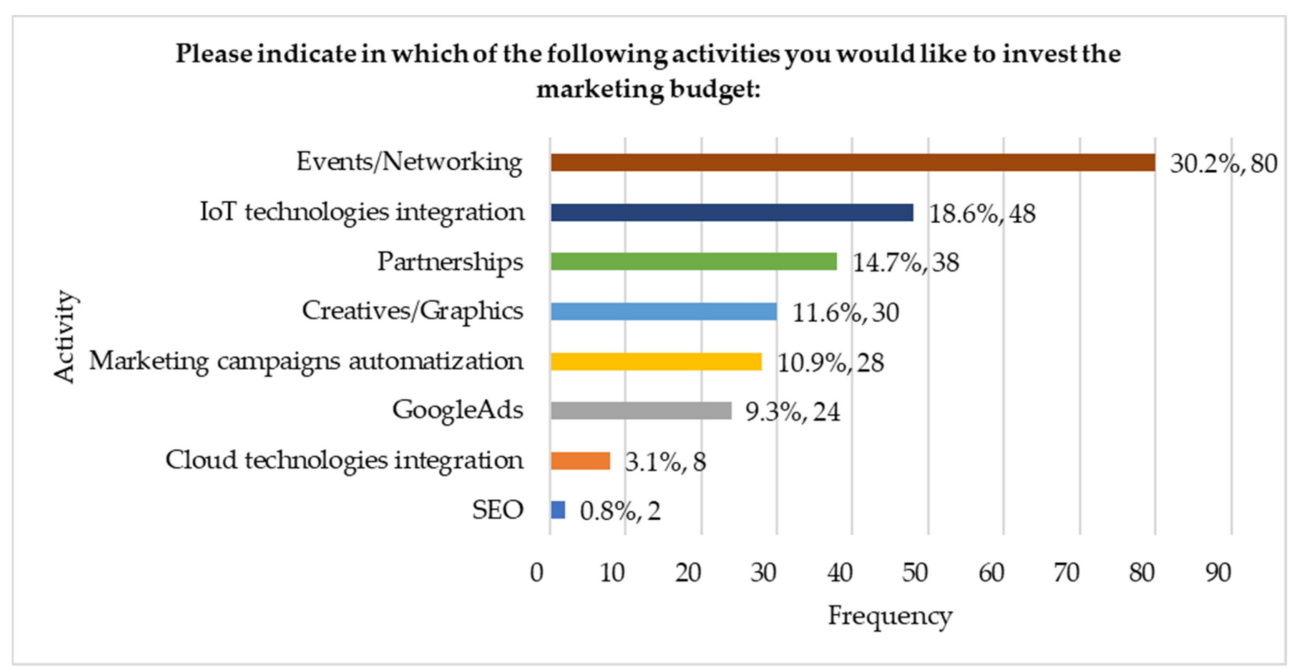

Figure 2. Actions targeted for the use of the marketing budget.

To identify the factors that influence the current or future integration of the IoT, the two hypotheses were tested.

The first hypothesis aimed to identify a possible connection between the advanced marketing technologies integration and organizations' expansion to new locations (the number of new locations opened by the companies). To test the hypothesis, the following were considered: a binary variable related to the integration of advanced marketing technologies by the organization and a nominal one with a single answer, which allowed for the determination of the size of the organization in terms of expansion to new locations.

According to the results presented in Figure 3, it was found that, at the sample level, the companies that do not expand their activities to new locations integrate advanced marketing technologies to a very small extent in their activity, while the companies with expanded activities in more than four locations do so to a greater extent. The situation is generated, firstly, by the available budget, because a company that manages to operate in several locations is considered to be a company with a greater financial power. At the same time, covering a wider segment of customers, in several geographical areas, can lead to a higher demand to follow the latest trends in technology. However, by comparing the number of companies that activate in a single location that integrate advanced marketing technologies with the organizations that have expanded their activities to two, three, or four new locations, a downward trend can be observed. Thus, it can be assumed that a company can afford to technologically grow only after it has reached a certain target; in this case, after the company has managed to expand its activity to more than four locations. The data results for the graphical representation in Figure 3 is available in Table A1 from Appendix A. 


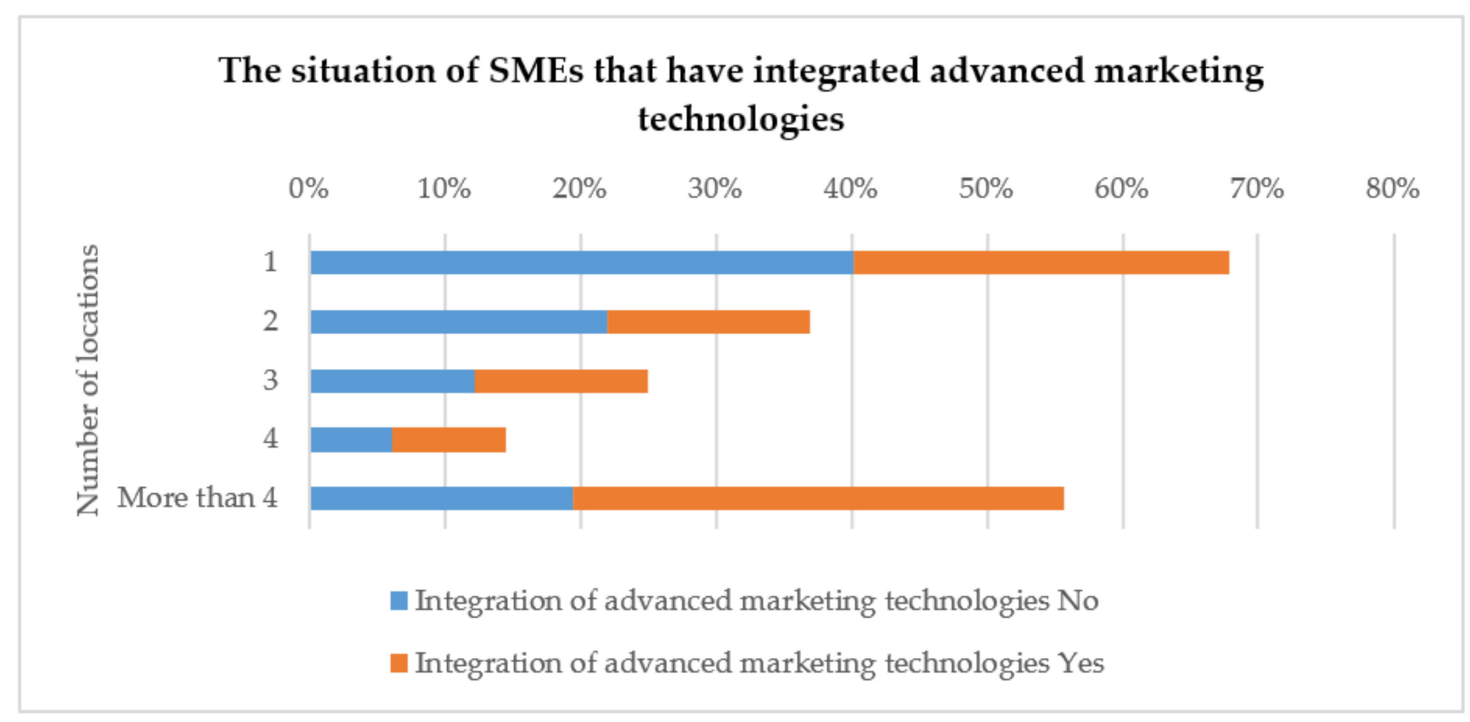

Figure 3. The situation of SMEs that have integrated advanced marketing technologies.

Thus, the analysis emphasized the differences among the two groups, suggesting a possible connection between the variables. Therefore, the Chi-Square method was used to test the statistical significance of this connection. The authors started from the null hypothesis, which assumed that there is no connection between the companies' expansion to new locations and the integration of advanced marketing technologies (H0). The test results are stated in the table below (Table 3 ).

Table 3. Chi-Square test results.

\begin{tabular}{cccc}
\hline & Values & Degrees of Freedom & Level of Significance \\
\hline Pearson Chi-Square & 11.185 & 4 & 0.025 \\
Likelihood Ratio & 11.077 & 4 & 0.026 \\
Number of valid cases & 258 & & \\
\hline
\end{tabular}

The value of $X_{\text {calc }}^{2}$ obtained by applying the test is equal to 11.185, which was compared with the theoretical value of $X_{20,0.05,4}^{2}=9.488$. Since $X_{\text {calc }}^{2}>X_{20,0.05,4}^{2}$, the null hypothesis, $\mathrm{H} 0$, is rejected, and this means that it can be guaranteed for a $95 \%$ probability that there is a connection between the integration of advanced marketing technologies and the companies expanding to new locations. The decision can also be made considering the minimum level of significance for which the alternative hypothesis (H1) can be accepted (Asymp. Sig $=0.025<\alpha=0.05$ ).

The second hypothesis highlighted the relationship between the size of organizations in terms of the number of employees and their relationship to the importance of the IoT integration in the area of marketing activities, especially to generate effective digital marketing strategies. The authors started from the premise that there is no well-defined connection between the size of companies in terms of employees and the level of importance given by the company to the IoT integration in the digital marketing strategy (H0). Two variables were considered: the IoT integration into the digital marketing strategy, and the size of the SMEs in terms of number of employees.

The results obtained (Figure 4, and Table A2 in Appendix A) emphasize that, at the sample level, the percentage of organizations with 150-249 employees that consider the integration of IoT in the digital marketing strategy to be very important, is higher than that of the companies with a lower number of employees. At the same time, the number of organizations with fewer than 50 employees that consider the IoT integration to not be important at all for their digital marketing strategy is larger than that of the larger companies. The analysis of the data in the table suggests the existence of differences 
between the groups, meaning that there may be a connection between the two variables. A statistical test was applied to determine the statistical significance of the connection. Since the test variable is measured on an ordinal scale and the identification variables consists of four groups, the authors applied the Median test.

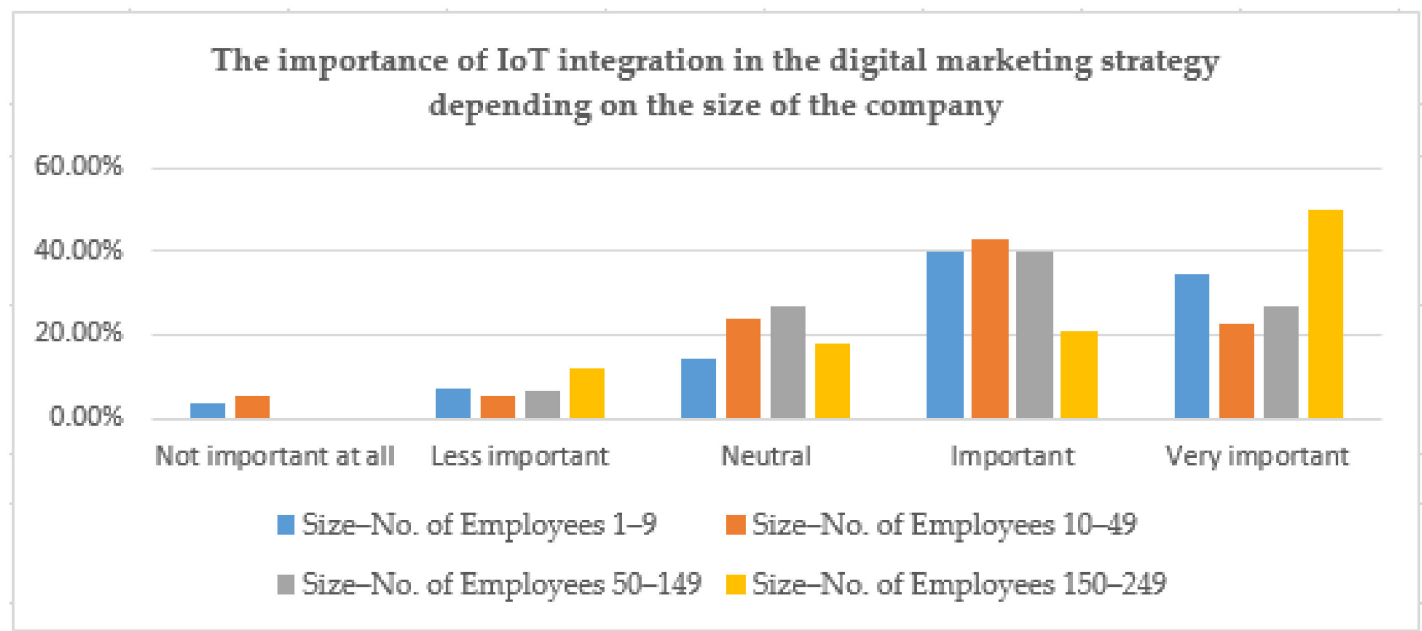

Figure 4. The importance of the IoT integration in digital marketing strategy depending on the size of the company.

Following the performed analyses in Tables 4 and 5, it was determined that the median is given by the answer "Important". The value of $X_{\text {calc }}^{2}$ obtained by applying the test is equal to 13.666, which was compared with the theoretical value of $X_{20,0.05,3}^{2}$, which is equal to 7.814 . Given that $X_{c a l c}^{2}>X_{20,0.05,4}^{2}$, the authors reject the null hypothesis, H0, and accept the alternative hypothesis, H1, which means that it can be guaranteed for a $95 \%$ probability that there is a connection between the size of the companies depending on the number of employees and the level of importance considered for the integration of IoT technologies in the digital marketing campaigns. The same decision can be made based on the minimum level of significance for which the alternative hypothesis (H1) is accepted (Asymp. Sig $=0.004<\alpha=0.05$ ).

Table 4. Frequencies observed below and above the median level.

\begin{tabular}{ccccc}
\hline & \multicolumn{4}{c}{ Frequencies } \\
\hline & $\mathbf{1 - 9}$ & Size-Number of Employees \\
\cline { 2 - 5 } & 19 & $\mathbf{1 0 - 4 9}$ & $\mathbf{5 0 - 1 4 9}$ & $\mathbf{1 5 0 - 2 4 9}$ \\
\hline Median & 36 & 17 & 16 & 34 \\
$\leq$ Median & 58 & 44 & 34 \\
\hline
\end{tabular}

Table 5. Median test.

\begin{tabular}{lc}
\hline & Test Statistics \\
\hline Sample size & 258 \\
Median & 4 \\
Hi square test value & 13.576 \\
Degrees of freedom & 3 \\
Level of significance & 0.004 \\
\hline
\end{tabular}

\section{Conclusions and Proposals}

In order to be competitive and grow in a sustainable manner, the SMEs must be innovative and adopt new technologies so that innovation becomes the driving force of their development [51]. The information presented approves the results of other research published in the literature on the issue of digitalization in general, but also on the IoT integration in particular, especially for SMEs $[23,32,53,64-68]$. The research identified and 
complexly analyzed the opinions, behaviors, and attitudes of the representatives of the Romanian SMEs of the IT industry by approaching the adoption of the IoT technologies as a manner for such companies to achieve sustainable growth strictly in terms of internal processes, taking into account the opinions of people that are directly involved in the organization actions, such as internally specialized staff. The SMEs represent an important segment of the Romanian economy, which even if it presents great potential, still struggles to find and implement innovative and sustainable strategies in order to achieve growth $[2,10]$. Thus, the novelty and utility of the study consists in rigorously analyzing the Romanian SMEs in terms of assessing and using the technology for sustainable growth. Moreover, the study benefits the decision makers (of both SMEs and the government) in terms of creating sustainable growth plans and strategies in which advanced technologies such as the IoT to be exploited to their full potential.

The results obtained can be useful for both the business and academic environment because, referring to the investment in advanced technologies, it is observed that over half of the companies do not integrate technologies such as the IoT.

Given the current trends in the transformation of universities into entrepreneurial universities, academia can also make an important contribution, by offering consultancy in various field, for the sustainable development of SMEs, by initiating collaborations that can benefit both partners [73,74].

However, the integration of the IoT ranks second in the top of preferences when it comes to using the marketing budget in the future. The research proved that there is a connection between the expansion to new locations by the companies and the integration of advanced marketing technologies. Thus, the geographical expansion of the company can also support the development from a technological point of view. On the other hand, the size of the company in terms of employees influences the perception of the importance of the IoT integration. The SMEs with over 50 employees consider this aspect to be important for the development of an effective digital marketing strategy. In this regard, the authors suggest the business environment the design of viable marketing programs, as well as the allocation of resources for the business development, aimed at educating the human resources, to be able to effectively address the specific internal and external activities through the IoT. The existence of coherent development plans could lead to the rapid growth of the popularity of the IoT technologies by using the existing resources of the companies, combined with the allocation of some new resources (in terms of staff, technologies, know-how etc.).

The research has certain limitations. The main limitation was the particularities of the studied companies and the reluctance of some employees of the SMEs in the IT industry to respond. The inability to assist the respondents in real-time, and the distribution of questionnaires strictly in the online environment are other limiting conditions of this research. For the smaller (1-9 employees) and relatively new SMEs on the market, there was fear and refusal to answer certain questions, which resulted in a series of incomplete questionnaires, and thus in a slightly increased margin of error for the sample (5.27\%).

Future research directions should aim at conducting studies to determine how companies will be able to address in a more efficient manner the issues related to the specific internal and external activities by using the IoT technology, in order to achieve a sustainable growth. The results of such studies should provide companies with support in developing marketing programs that are properly adapted to the market changes, and by coherently developing educational policies for employees. Another important topic recommended by the authors refers to monitoring the integration process of the new marketing technologies within the companies, in order to identify the optimal time for the adoption, and the resources involved in this process.

Author Contributions: Conceptualization, A.-D.S., A.I.M.T., G.B., I.B.C., and L.D.; methodology, A.-D.S., A.I.M.T., G.B., and L.D.; writing-original draft preparation, A.-D.S., A.I.M.T., I.B.C., G.B., and L.D.; writing-review and editing, A.-D.S., A.I.M.T., I.B.C., G.B., and L.D.; supervision, G.B.; All authors have read and agreed to the published version of the manuscript. 
Funding: This research was funded by the TRANSILVANIA UNIVERSITY OF BRASOV.

Institutional Review Board Statement: Ethical review and approval were waived for this study, due to the absence of sensitive data and to the processing of data by ensuring confidentiality and anonymization of the personal information for all the subjects involved in the study.

Informed Consent Statement: Informed consent was obtained from all the participants in this study.

Data Availability Statement: Data presented in this study are available upon request from the authors. The data are not publicly available due to privacy issues.

Conflicts of Interest: The authors declare no conflict of interest.

\section{Appendix A. Research Results}

Table A1. The situation of SMEs that have integrated advanced marketing technologies.

\begin{tabular}{cccc}
\hline \multirow{2}{*}{ Number of Locations } & \multicolumn{2}{c}{ Integration of Advanced Marketing Technologies } & Total \\
\cline { 2 - 4 } & No & Yes & $35.7 \%$ \\
\hline 1 & $40.2 \%$ & $27.7 \%$ & $19.4 \%$ \\
2 & $22.0 \%$ & $14.9 \%$ & $12.3 \%$ \\
4 & $12.2 \%$ & $12.8 \%$ & $7.0 \%$ \\
More than 4 & $6.1 \%$ & $8.4 \%$ & $25.6 \%$ \\
Total & $19.5 \%$ & $36.2 \%$ & $100.0 \%$ \\
\hline
\end{tabular}

Table A2. The importance of IoT integration in digital marketing strategy depending on the size of the company.

\begin{tabular}{cccccc}
\hline \multirow{2}{*}{$\begin{array}{c}\text { Integrating IoT into the Digital } \\
\text { Marketing Strategy }\end{array}$} & \multicolumn{3}{c}{ Size-No. of Employees } & \multirow{2}{*}{ Total } \\
\cline { 2 - 5 } & $\mathbf{1 - 9}$ & $\mathbf{1 0 - 4 9}$ & $\mathbf{5 0 - 1 4 9}$ & $\mathbf{1 5 0 - 2 4 9}$ & \\
\hline Not important at all & $3.6 \%$ & $5.3 \%$ & $0.0 \%$ & $0.0 \%$ & $2.3 \%$ \\
Less important & $7.3 \%$ & $5.3 \%$ & $6.7 \%$ & $11.8 \%$ & $7.8 \%$ \\
Neutral & $14.5 \%$ & $24.0 \%$ & $26.7 \%$ & $17.6 \%$ & $20.9 \%$ \\
Important & $40.0 \%$ & $42.7 \%$ & $40.0 \%$ & $20.6 \%$ & $35.7 \%$ \\
Very important & $34.5 \%$ & $22.7 \%$ & $26.7 \%$ & $50.0 \%$ & $33.3 \%$ \\
\hline Total & $100.0 \%$ & $100.0 \%$ & $100.0 \%$ & $100.0 \%$ & $100.0 \%$ \\
\hline
\end{tabular}

\section{References}

1. Assante, D.; Romano, E.; Flamini, M.; Castro, M.; Martin, S.; Lavirotte, S.; Rey, G.; Leisenberg, M.; Migliori, M.O.; Bagdoniene, I.; et al. Internet of Things education: Labor market training needs and national policies. In Proceedings of the 2018 IEEE Global Engineering Education Conference (EDUCON), Santa Cruz de Tenerife, Spain, 17-20 April 2018; pp. 1846-1853.

2. Obi, J.; Ibidunni, A.S.; Tolulope, A.; Olokundun, M.A.; Amaihian, A.B.; Borishade, T.T.; Fred, P. Contribution of small and medium enterprises to economic development: Evidence from a transiting economy. Data Brief 2018, 18, 835-839. [CrossRef] [PubMed]

3. Elkhalek, D.A. SMEs' Contribution to Sustainable Development; an Applied Study Focusing on OECD Countries. IOSR J. Econ. Financ. 2019, 10, 69-78.

4. OECD SME and Entrepreneurship Outlook 2019; OECD Publishing: Paris, France; Available online: https://www.oecd-ilibrary.org/ sites/34907e9c-en/index.html?itemId=/content/publication/34907e9c-en (accessed on 26 March 2021).

5. European Commission. SBA Fact Sheet. 2019. Available online: https://ec.europa.eu/docsroom/documents/38662/ attachments/24/translations/en/renditions/native (accessed on 26 March 2021).

6. Novak, J.; Purta, M.; Marciniak, T.; Ignatowicz, K.; Rozenbaum, K.; Yearwood, K. The Rise of Digital Challengers How Digitization Can Become the Next Growth Engine for Central and Eastern Europe 2018. Available online: https://www.mckinsey.com (accessed on 26 March 2021).

7. European Commission. Digital Economy and Society Index (DESI) 2020. Available online: https://ec.europa.eu/digital-singlemarket/en/scoreboard/romania (accessed on 12 November 2020).

8. Kumar, R.; Singh, R.K.; Dwivedi, Y.K. Application of industry 4.0 technologies in SMEs for ethical and sustainable operations: Analysis of challenges. J. Clean. Prod. 2020, 275, 124063. [CrossRef]

9. Cașotă, F. Digitization Has Reduced the Negative Impact of the COVID-19 Pandemic on SMEs, Start-Up. 2020. Available online: https:/ / start-up.ro/digitalizarea-a-micsorat-impactul-negativ-al-pandemiei-covid-19-asupra-imm-urilor/ (accessed on 12 November 2020). 
10. Türkeș, M.C.; Oncioiu, I.; Aslam, H.D.; Marin-Pantelescu, A.; Topor, D.I.; Căpușneanu, S. Drivers and Barriers in Using Industry 4.0: A Perspective of SMEs in Romania. Process 2019, 7, 153. [CrossRef]

11. Neagu, C. The importance and role of small and medium-sized businesses. Theor. Appl. Econ. 2016, XXIII, 331-338.

12. Maiorescu, I.; Bucur, M.; Georgescu, B.; Moise, D.; Strat, V.; Zgură, I. Social Media and IOT Wearables in Developing Marketing Strategies. Do SMEs Differ From Large Enterprises? Sustainability 2020, 12, 7292. [CrossRef]

13. Wu, J.; Feng, Y.; Sun, P. Sensor Fusion for Recognition of Activities of Daily Living. Sensors 2018, 18, 4029. [CrossRef]

14. Mohammadi, F.; Nazri, G.-A.; Saif, M. A Real-Time Cloud-Based Intelligent Car Parking System for Smart Cities. In Proceedings of the 2019 IEEE 2nd International Conference on Information Communication and Signal Processing (ICICSP), Weihai, China, 28-30 September 2019; pp. 235-240.

15. Pele, A. IMM-Urile: O Hartă a Specificului Românesc Desenată de UE, Curs de Guvernare.Ro. 2018. Available online: https: / / cursdeguvernare.ro/profilul-antreprenorial-al-romaniei.html (accessed on 25 March 2021).

16. Trigo, A.; Varajão, J.; Barroso, J.; Soto-Acosta, P.; Molina-Castillo, F.J.; Gonzalvez-Gallego, N. Enterprise information systems adoption in Iberian large companies: Motivations and trends. In Managing Adaptability, Intervention, and People in Enterprise Information Systems; IGI Global: Hershey, PA, USA, 2011; pp. 204-228.

17. Horváth, D.; Szabó, R.Z. Driving forces and barriers of Industry 4.0: Do multinational and small and medium-sized companies have equal opportunities? Technol. Forecast. Soc. Chang. 2019, 146, 119-132. [CrossRef]

18. Moeuf, A.; Pellerin, R.; Lamouri, S.; Tamayo-Giraldo, S.; Barbaray, R. The industrial management of SMEs in the era of Industry 4.0. Int. J. Prod. Res. 2018, 56, 1118-1136. [CrossRef]

19. Moeuf, A.; Lamouri, S.; Pellerin, R.; Tamayo-Giraldo, S.; Tobon-Valencia, E.; Eburdy, R. Identification of critical success factors, risks and opportunities of Industry 4.0 in SMEs. Int. J. Prod. Res. 2020, 58, 1384-1400. [CrossRef]

20. Chege, S.M.; Wang, D. The influence of technology innovation on SME performance through environmental sustainability practices in Kenya. Technol. Soc. 2020, 60, 101210. [CrossRef]

21. Somohano-Rodríguez, F.M.; Madrid-Guijarro, A.; López-Fernández, J.M. Does Industry 4.0 really matter for SME innovation? J. Small Bus. Manag. 2020, 1-28. [CrossRef]

22. Brunswicker, S.; Vanhaverbeke, W. Open Innovation in Small and Medium-Sized Enterprises (SMEs): External Knowledge Sourcing Strategies and Internal Organizational Facilitators. J. Small Bus. Manag. 2015, 53, 1241-1263. [CrossRef]

23. Atzori, L.; Iera, A.; Morabito, G. Understanding the Internet of Things: Definition, potentials, and societal role of a fast evolving paradigm. Ad Hoc Netw. 2017, 56, 122-140. [CrossRef]

24. Ahmed, B.S.; Bures, M.; Frajtak, K.; Cerny, T. Aspects of Quality in Internet of Things (IoT) Solutions: A Systematic Mapping Study. IEEE Access 2019, 7, 13758-13780. [CrossRef]

25. Shin, D.-I. An exploratory study of innovation strategies of the internet of things SMEs in South Korea. Asia Pac. J. Innov. Entrep. 2017, 11, 171-189. [CrossRef]

26. Wortmann, A.-P.D.F.; Flüchter, K. Internet of Things. Bus. Inf. Syst. Eng. 2015, 57, 221-224. [CrossRef]

27. Tsai, C.-W.; Lai, C.-F.; Vasilakos, A.V. Future Internet of Things: Open issues and challenges. Wirel. Netw. 2014, 20, 2201-2217. [CrossRef]

28. Whitmore, A.; Agarwal, A.; Da Xu, L. The Internet of Things-A survey of topics and trends. Inform. Syst Front. 2015, 17, 261-274. [CrossRef]

29. Silverio-Fernández, M.; Renukappa, S.; Suresh, S. What is a smart device?-A conceptualisation within the paradigm of the internet of things. Vis. Eng. 2018, 6, 3. [CrossRef]

30. Gubbi, J.; Buyya, R.; Marusic, S.; Palaniswami, M.S. Internet of Things (IoT): A vision, architectural elements, and future directions. Futur. Gener. Comput. Syst. 2013, 29, 1645-1660. [CrossRef]

31. Spilotro, C.E. Connecting the Dots: How IoT Is Going to Revolutionize the Digital Marketing Landscape for Millennials. Undergraduate Honors Theses. 2016. Available online: https:/ / digital.sandiego.edu/honors_theses / 25 (accessed on 1 November 2020).

32. Lo, F.-Y.; Campos, N. Blending Internet-of-Things (IoT) solutions into relationship marketing strategies. Technol. Forecast. Soc. Chang. 2018, 137, 10-18. [CrossRef]

33. Prieger, J.E.; Heil, D. Economic Implications of e-Business for Organizations. In Progress in IS; Springer Science and Business Media LLC: Berlin/Heidelberg, Germany, 2014; pp. 15-53.

34. Pérez-Aróstegui, M.N.; Martínez-López, F.J. IT Competence-Enabled Business Performance and Competitive Advantage. In Progress in IS; Springer Science and Business Media LLC: Berlin/Heidelberg, Germany, 2014; pp. 109-138.

35. Abazi, B. An approach to the impact of transformation from the traditional use of ICT to the Internet of Things: How smart solutions can transform SMEs. IFAC-Pap. 2016, 49, 148-151. [CrossRef]

36. Bouwman, H.; Nikou, S.; de Reuver, M. Digitalization, business models, and SMEs: How do business model innovation practices improve performance of digitalizing SMEs? Telecommun. Policy 2019, 43, 101828. [CrossRef]

37. Isensee, C.; Teuteberg, F.; Griese, K.-M.; Topi, C. The relationship between organizational culture, sustainability, and digitalization in SMEs: A systematic review. J. Clean. Prod. 2020, 275, 122944. [CrossRef]

38. Matarazzo, M.; Penco, L.; Profumo, G.; Quaglia, R. Digital transformation and customer value creation in Made in Italy SMEs: A dynamic capabilities perspective. J. Bus. Res. 2021, 123, 642-656. [CrossRef] 
39. Fjellström, D.; Osarenkhoe, A.; Pettersson, T.; Tadesse, D. The Role of Digitalization in SMEs' Strategy Development: The Case of Sweden. In Palgrave Studies in Cross-Disciplinary Business Research, in Association with EuroMed Academy of Business; Springer Science and Business Media LLC: Berlin/Heidelberg, Germany, 2020; pp. 65-88.

40. Pizzi, S.; Corbo, L.; Caputo, A. Fintech and SMEs sustainable business models: Reflections and considerations for a circular economy. J. Clean. Prod. 2021, 281. [CrossRef]

41. Paiola, M. Digitalization and servitization: Opportunities and challenges for Italian SMES. Sinergie Ital. J. Manag. 2018, 36, 11-22.

42. Santini, F.D.O.; Kretschmer, C.; Marconatto, D.A.B. Antecedents, consequents and moderators of business models in SMEs: A meta-analytical research study. J. Small Bus. Entrep. 2020, 1-32. [CrossRef]

43. Sjödin, D.; Parida, V.; Jovanovic, M.; Visnjic, I. Value Creation and Value Capture Alignment in Business Model Innovation: A Process View on Outcome-Based Business Models. J. Prod. Innov. Manag. 2019, 37, 158-183. [CrossRef]

44. Brous, P.; Janssen, M.; Herder, P. The dual effects of the Internet of Things (IoT): A systematic review of the benefits and risks of IoT adoption by organizations. Int. J. Inf. Manag. 2020, 51, 101952. [CrossRef]

45. Müller, J.M.; Buliga, O.; Voigt, K.-I. The role of absorptive capacity and innovation strategy in the design of industry 4.0 business Models-A comparison between SMEs and large enterprises. Eur. Manag. J. 2020. [CrossRef]

46. Müller, J.M.; Buliga, O.; Voigt, K.-I. Fortune favors the prepared: How SMEs approach business model innovations in Industry 4.0. Technol. Forecast. Soc. Chang. 2018, 132, 2-17. [CrossRef]

47. Reil, H.; Rimbeck, M.; Leyer, M.; Stumpf-Wollersheim, J. Understanding the consequences of adopting the Internet of Things in small- and medium-sized enterprises. In Proceedings of the PACIS 2020 Proceedings, Dubai, UAE, $20-24$ June 2020.

48. Peter, M.K.; Kraft, C.; Lindeque, J. Strategic action fields of digital transformation: An exploration of the strategic action fields of Swiss SMEs and large enterprises. JSMA 2020, 13, 160-180. [CrossRef]

49. Haseeb, M.; Hussain, H.I.; Ślusarczyk, B.; Jermsittiparsert, K. Industry 4.0: A Solution towards Technology Challenges of Sustainable Business Performance. Soc. Sci. 2019, 8, 154. [CrossRef]

50. Mohammadian, H.D. IoT-Education technologies as solutions towards SMEs' educational challenges and I4.0 readiness. In Proceedings of the IEEE Global Engineering Education Conference (EDUCON), Porto, Portugal, 27-30 April 2020; pp. 1674-1683.

51. Qalati, S.A.; Li, W.; Ahmed, N.; Mirani, M.A.; Khan, A. Examining the Factors Affecting SME Performance: The Mediating Role of Social Media Adoption. Sustainability 2020, 13, 75. [CrossRef]

52. Ziółkowska, M. Digital Transformation and Marketing Activities in Small and Medium-Sized Enterprises. Sustainability 2021, 13, 2512. [CrossRef]

53. Parra, D.T.; Guerrero, C.D. Decision-making IoT adoption in SMEs from a technological perspective. In Proceedings of the 2020 15th Iberian Conference on Information Systems and Technologies (CISTI), Sevilla, Spain, 24-27 June 2020; pp. 1-6.

54. Fitriasari, F. How do Small and Medium Enterprise (SME) survive the COVID-19 outbreak? J. Inov. Èkon. 2020, 5. [CrossRef]

55. Garzoni, A.; De Turi, I.; Secundo, G.; Del Vecchio, P. Fostering digital transformation of SMEs: A four levels approach. Manag. Decis. 2020, 58, 1543-1562. [CrossRef]

56. Ifinedo, P. An empirical analysis of factors influencing Internet / e-business technologies adoption by SMEs in Canada. Int. J. Inf Tech. Decis 2011, 10, 731-766. [CrossRef]

57. García, J.J.L.; Lizcano, D.; Ramos, C.M.; Matos, N. Digital Marketing Actions That Achieve a Better Attraction and Loyalty of Users: An Analytical Study. Futur. Internet 2019, 11, 130. [CrossRef]

58. Molina-Castillo, F.-J.; Lopez-Nicolas, C.; Soto-Acosta, P. Interaction effects of media and message on perceived complexity, risk and trust of innovative products. Eur. Manag. J. 2012, 30, 577-587. [CrossRef]

59. Arkhipova, N.I.; Gurieva, M.T. Modern trends in the development of digital marketing. RSUH/RGGU Bull. Econ. Series. Manag. Law 2018.

60. Kannan, P.; Li, H. “Alice” Digital marketing: A framework, review and research agenda. Int. J. Res. Mark. 2017, 34, 22-45. [CrossRef]

61. Nichifor, E.; Trifan, A.; Nechifor, E.M. Artificial Intelligence in Electronic Commerce: Basic Chatbots and Consumer Journey. Amfiteatru Econ. 2021, 23, 87-101. [CrossRef]

62. Adam, M.; Ibrahim, M.; Ikramuddin, I.; Syahputra, H. The Role of Digital Marketing Platforms on Supply Chain Management for Customer Satisfaction and Loyalty in Small and Medium Enterprises (SMEs) at Indonesia. IJSCM 2020, 9, 1210-1220.

63. Shpak, N.; Kuzmin, O.; Dvulit, Z.; Onysenko, T.; Sroka, W. Digitalization of the Marketing Activities of Enterprises: Case Study. Information 2020, 11, 109. [CrossRef]

64. Malesev, S.; Cherry, M. Digital and Social Media Marketing-Growing Market Share for Construction SMEs. Constr. Econ. Build. 2021, 21. [CrossRef]

65. Taiminen, H.M.; Karjaluoto, H. The usage of digital marketing channels in SMEs. J. Small Bus. Enterp. Dev. 2015, $22,633-651$. [CrossRef]

66. Masood, T.; Sonntag, P. Industry 4.0: Adoption challenges and benefits for SMEs. Comput. Ind. 2020, 121, 103261. [CrossRef]

67. Mogos, R.I. Digital Marketing for Identifying Customers' Preferences-A Solution for SMEs in Obtaining Competitive Advantages. IJEPT 2015, 5, 240-247.

68. Dumitriu, D.; Militaru, G.; Deselnicu, D.C.; Niculescu, A.; Popescu, M.A.-M. A Perspective over Modern SMEs: Managing Brand Equity, Growth and Sustainability Through Digital Marketing Tools and Techniques. Sustainability 2019, 11, 2111. [CrossRef]

69. European Commission. User's Manual for the Definition of SMEs; Publications Office of the European Union: Luxembourg, 2015. 
70. List of Romanian Companies. Available online: https://membri.listafirme.ro/pagini/p1.htm (accessed on 1 June 2020).

71. Fisher, R.A. On the Interpretation of $\chi 2$ from Contingency Tables, and the Calculation of P. J. R. Stat. Soc. 1922, 85, 87. [CrossRef]

72. Siegel, S.; Castellan, N.J., Jr. Nonparametric Statistics for the Behavioural Sciences; McGraw-Hill: New York, NY, USA, 1988; ISBN 13:978-0070573574.

73. Kurdve, M.; Bird, A.; Laage-Hellman, J. Establishing SME-university collaboration through innovation support programmes. J. Manuf. Technol. Manag. 2020, 31, 1583-1604. [CrossRef]

74. Brătucu, G.; Lixăndroiu, R.C.; Constantin, C.P.; Tecău, A.S.; Chițu, I.B.; Trifan, A. Entrepreneurial University: Catalyst for Regional Sustainable Development. Sustainability 2020, 12, 4151. [CrossRef] 